MRS Advances (C) 2019 Materials Research Society. This is an Open Access article, distributed under the terms of the Creative Commons Attribution licence (http:// creativecommons.org/licenses/by/4.0/), which permits unrestricted re-use, distribution, and reproduction in any medium, provided the original work is properly cited.

DOI: 10.1557/adv.2019.142

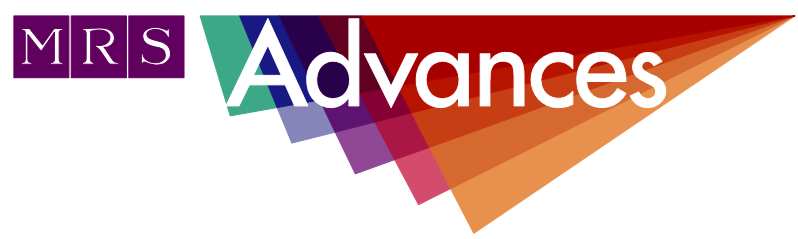

\title{
Characterization of AlN-based Ceramic Composites for Use as Millimeter Wave Susceptor Materials at High Temperature: High Temperature Thermal Properties of AlN:Mo with $0.25 \%$ to $4.0 \%$ Mo by Volume
}

Brad W. Hoff ${ }^{1}$, Frederick W. Dynys ${ }^{2}$, Steven C. Hayden ${ }^{3}$, Rachael O. Grudt ${ }^{3}$, Martin S. Hilario $^{1}$, Anthony E. Baros ${ }^{1}$, Michele L. Ostraat ${ }^{3}$

${ }^{1}$ Air Force Research Laboratory, Kirtland AFB, NM, 87117, USA

${ }^{2}$ NASA Glenn Research Center, Cleveland, Ohio 44135, USA

${ }^{3}$ Aramco Research Center - Boston, Aramco Services Company, Cambridge, MA 02139, USA

ABSTRACT

In order to begin to evaluate and model the suitability of high temperature ceramic composites, such as AlN:Mo, as susceptor materials for power beaming applications, the electromagnetic, thermal, and mechanical properties of the material must be known at elevated temperatures. Work reported here focuses on the development of thermal property datasets for AlN:Mo composites ranging from $0.25 \%$ to $4.0 \%$ Mo by volume. To calculate thermal conductivity of the AlN:Mo composite series, specific heat capacity, thermal diffusivity, and density data were acquired. The calculated specific heat capacity, $C_{p}$, of the set of AlN:Mo composites was, on average, found to be approximately $803 \mathrm{~J} / \mathrm{kgK}$ at $100{ }^{\circ} \mathrm{C}$ and to increase to approximately $1133 \mathrm{~J} / \mathrm{kgK}$ at $1000^{\circ} \mathrm{C}$, with all values to be within $+/-32$ $\mathrm{J} / \mathrm{kgK}$ of the average at a given temperature. These calculated specific heat capacity values matched values derived from DSC measurements to within the expected error of the measurements. Measured thermal diffusivity, $\alpha$, of the set of AlN:Mo composites was, on average, found to be approximately $3.93 \times 10^{-1} \mathrm{~cm}^{2} / \mathrm{s}$ at $100^{\circ} \mathrm{C}$ and to increase to approximately $9.80 \times 10^{-2} \mathrm{~cm}^{2} / \mathrm{s}$ at $1000^{\circ} \mathrm{C}$, with all values within $+/-1.84 \times 10^{-2} \mathrm{~cm}^{2} / \mathrm{s}$ of the average at a given temperature. Thermal conductivity, $k$, for the set of AlN:Mo composites was found to be approximately $108 \mathrm{~W} / \mathrm{mK}$ at $100^{\circ} \mathrm{C}$ and to decrease to approximately 38 $\mathrm{W} / \mathrm{mK}$ at $1000^{\circ} \mathrm{C}$, with all values within $+/-5.3 \mathrm{~W} / \mathrm{mK}$ of the average at a given temperature. 
Data trends show that increasing Mo content correlates to lower values of of $C_{p}$, $\alpha$, and $k$ at a given temperature.

\section{INTRODUCTION:}

In some wireless power transfer systems employing thermo-mechanical conversion methodologies [1]-[3], bulk susceptor materials are required to convert microwave or millimeter wave radiation into thermal power, which is, in turn, converted into electrical power by external means. These bulk susceptor materials may take the form of composite materials generated through the combination of a high-thermalconductivity ceramic matrix and radiation-absorbing additives, such as lossy ceramics or metal particles [1].

For ease of design, the effective dielectric loss of the susceptor composite should be dominated by contributions from the additive material. Additionally, the temperature-dependent dielectric loss of the composite should be as weakly exponential as achievable, in order to limit the likelihood of thermal runaway effects [4] and to better enable optimal material performance over a wide range of operating temperatures.

One such ceramic composite system presently under investigation for use as a W-band $(75 \mathrm{GHz}-110 \mathrm{GHz}) \mathrm{mm}$-wave susceptor material is aluminum nitride containing metallic molybdenum powder (AlN:Mo). In order to evaluate and model [5] the suitability of such AlN:Mo composites as susceptor materials, the electromagnetic, thermal, and mechanical properties of the material must be known at elevated temperatures.

The work described herein focuses on the thermal properties of commercially available [6], hot pressed AlN:Mo composites in the additive range of $0.25 \%$ to $4 \% \mathrm{Mo}$ (by volume). AlN:Mo composites with Mo loading in this range have been identified as likely candidate materials for future power beaming experiments by the coauthors [1]. As described in Ref. [5], multiphysics modeling of ceramic composites in a heat exchanger configuration requires temperature-dependent specific heat capacity $\left(\mathrm{C}_{\mathrm{p}}\right)$ data (at constant pressure) and thermal conductivity (k) data over the temperature range of interest.

\section{X-RAY DIFFRACTION (XRD) COMPOSITIONAL ANALYSIS}

For crystallinity and phase analysis, x-ray diffraction (XRD) was performed using a Bruker D8 Discover diffractometer equipped with a copper tube $(1=0.15418$ $\mathrm{nm}$ ), and a VANTEC-500 2-D detector. XRD spectra were measured with a $2 \theta$ range of $10^{\circ}$ to $100^{\circ}$ in steps of $15^{\circ}$, with a collection time of $300 \mathrm{~s}$ per step. XRD characterization data for weight percentage analysis were collected with $2 \theta$ range of $15^{\circ}$ to $105^{\circ}$ in steps of $10^{\circ}$, again with a collection time of $300 \mathrm{~s}$ per step. XRD spectra and structural information for 4 phases $\left(\mathrm{AlN}, \mathrm{Mo}, \mathrm{Mo}_{2} \mathrm{C}\right.$, and $\mathrm{YAlO}_{3}$ ) were imported into Bruker DIFFRAC.TOPAS software, and Rietveld structural refinement was utilized to ascertain the weight percentage of each phase.

The XRD analysis (Figure 1) revealed a highly crystalline AlN matrix with non-matrix phase concentrations that increased with nominal loading percentages, as is evidenced by the increasing intensity of the Mo peaks across the series (Figure 1, zoom). Peaks associated with the $\mathrm{Mo}_{2} \mathrm{C}$ phase appear at $0.5 \%$ loading and remain approximately the same in intensity with further loading, and $\mathrm{YAlO}_{3}$ peaks have constant intensity across all Mo loadings. Phase breakdowns attained via Rietveld refinement of the XRD data are provided in Figure 2, where AlN is the balance. The $\mathrm{YAlO}_{3}$ phase forms during the sintering process as a product of the reaction between $\mathrm{Al}_{2} \mathrm{O}_{3}$ (present on the surface 
layers of un-sintered matrix AlN particles) and the sintering aid additive $\left(\mathrm{Y}_{2} \mathrm{O}_{3}\right)$ [7]-[9]. It is also noted that added Mo was found to react with carbon present in the matrix [7], [10] to form $\mathrm{Mo}_{2} \mathrm{C}$ up to an estimated concentration threshold of approximately $0.5 \%$ by volume. Beyond this threshold, additional Mo remains in the metallic state (Figure 2).

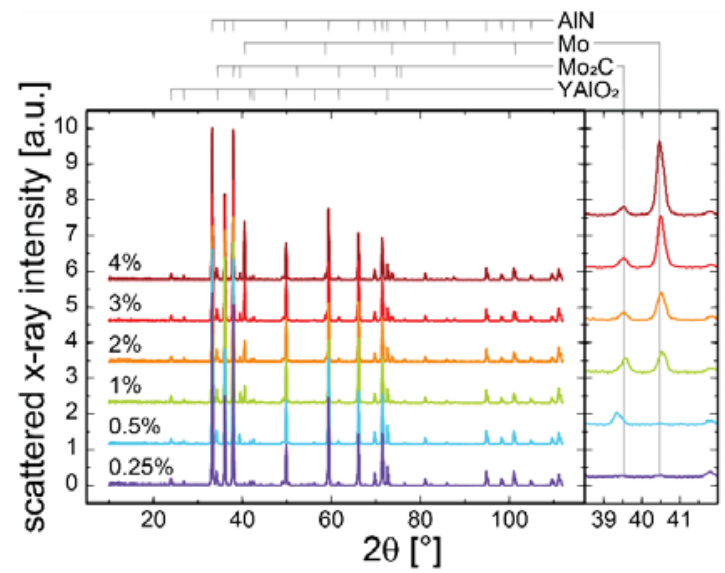

Figure 1. X-ray diffraction patterns AIN:Mo ceramic composites ranging from $0.25 \%$ to $4.0 \%$ Mo by volume.

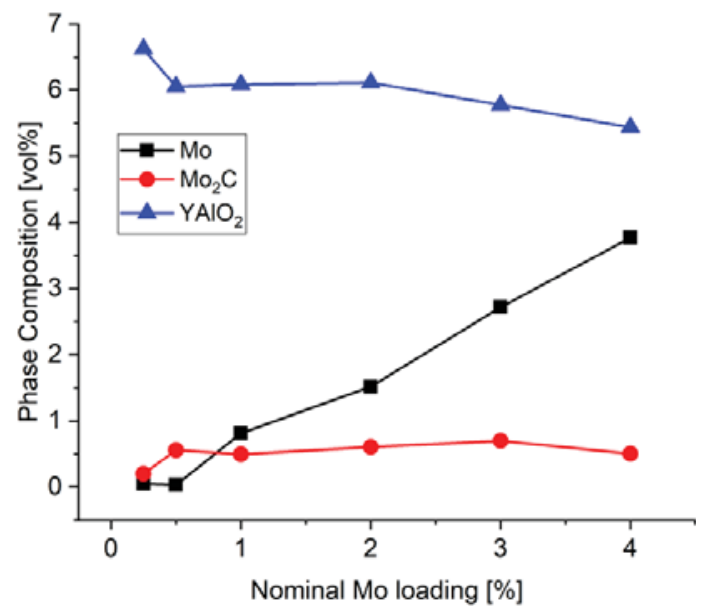

Figure 2. Phase analysis providing estimated volume percentages for AlN composites loaded with Mo at the nominal loading percentages as indicated. 


\section{DENSITY AND THERMAL PROPERTY CHARACTERIZATION}

\section{$\underline{\text { 3.1 Density Measurements }}$}

AlN:Mo sample density was measured by the Archimedes method using methyl ethyl ketone as the fluid. Measured densities are plotted in Figure 3 as a function of Mo content. AlN:Mo composite density, $\rho$, exhibits a linear relationship with percent Mo content (by volume), as described by Equation (1).

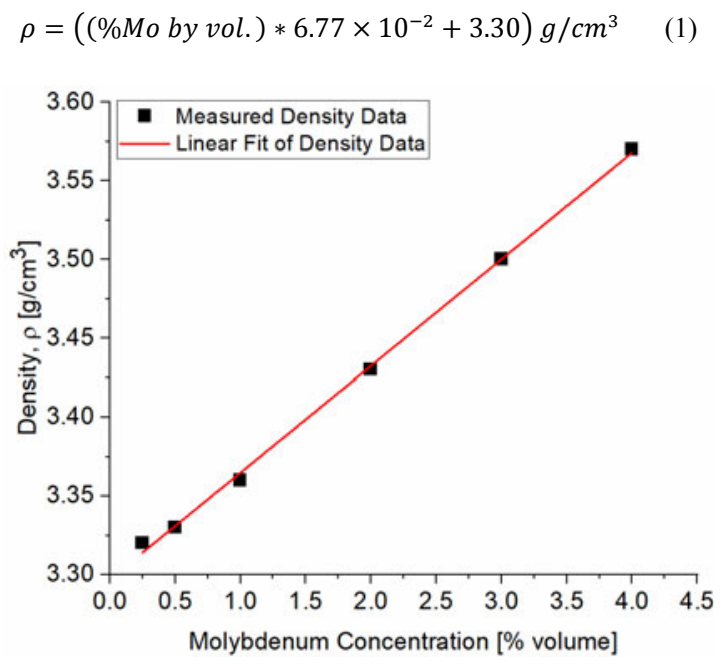

Figure 3. Measured density of AIN:Mo ceramic composites ranging from $0.25 \%$ to $4.0 \%$ Mo by volume.

\subsection{Specific Heat Capacity Calculations, Measurements, and Results}

Values for specific heat capacity at constant pressure $\left(\mathrm{C}_{\mathrm{p}}\right)$ for all six AlN:Mo compositions were calculated for temperatures up to $1000^{\circ} \mathrm{C}$. The specific heat capacity was calculated utilizing the rule of mixtures for $\mathrm{AlN}, \mathrm{Mo}, \mathrm{Mo}_{2} \mathrm{C}$, and $\mathrm{YAlO}_{3}$ under the assumption of non-reactivity between the phases [11]-[13]. Specific heat capacity data for constituent materials from NIST [14] (AIN and Mo); Liu, et al. [15] $\left(\mathrm{Mo}_{2} \mathrm{C}\right.$ ); and Hurst, et al. [16] $\left(\mathrm{YAlO}_{3}\right.$, using Kopp's Law) were used to calculate the composite specific heat capacity. Plots of calculated specific heat capacity data are displayed in Figure 4.

Three of the six AlN:Mo compositions ( $0.25 \%, 0.5 \%$, and $1.0 \%$ Mo by vol.) were measured using differential scanning calorimetry (DSC). Sample masses for the $0.25 \%, 0.5 \%$, and $1.0 \%$ Mo (by vol.) compositions used for DSC analysis were $56.8 \mathrm{mg}$, $59.5 \mathrm{mg}$, and $59.3 \mathrm{mg}$, respectively. The DSC utilized for the measurements was a TA Instruments SDT Q600. Platinum crucibles, having a thin layer of yttria on the bottom, contained the samples during measurement. A sapphire sample was used as the standard for the measurements. A heating rate of $20^{\circ} \mathrm{C} / \mathrm{min}$ was implemented for measurements of baselines, the sapphire standard, and the samples. Argon gas, at a flow rate of 50 $\mathrm{mL} / \mathrm{min}$, was used as the purge gas during measurements. 
Specific heat capacity $\left(\mathrm{C}_{\mathrm{p}}\right)$ values for the three AlN:Mo compositions were derived from DSC heat flux measurement data in the manner described by Ref. [17]. The measured $\mathrm{C}_{\mathrm{p}}$ data are compared to calculated $\mathrm{C}_{\mathrm{p}}$ data for AlN/Mo composites, as shown in Figure 4 for temperatures up to $600{ }^{\circ} \mathrm{C}$. Uncertainty of $\mathrm{C}_{\mathrm{p}}$ values obtained using DSC is $+/-5 \%$ from $30{ }^{\circ} \mathrm{C}$ to $600{ }^{\circ} \mathrm{C}$. The data trend shows that increasing Mo content corresponds to reduced $\mathrm{C}_{\mathrm{p}}$ values. The measured data exhibit a larger reduction of $\mathrm{C}_{\mathrm{p}}$ with increasing Mo content than do the calculated data.

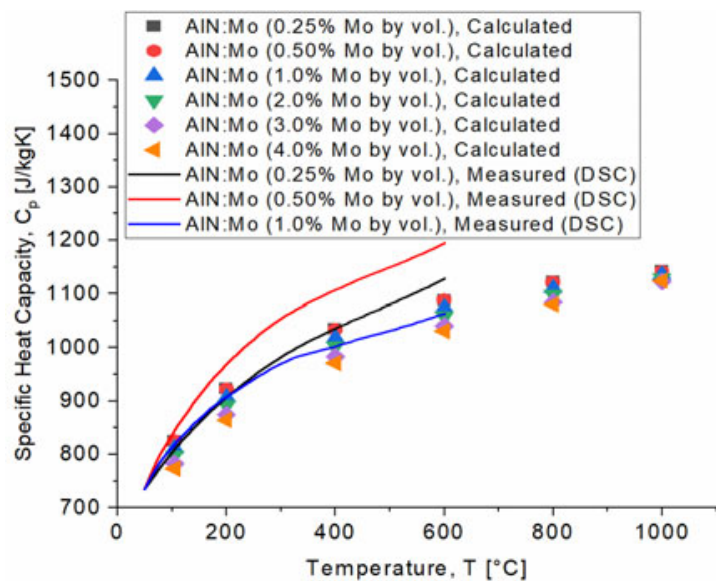

Figure 4. High temperature calculated and measured specific heat capacity data for AIN:Mo composites ranging from $0.25 \%$ to $4.0 \%$ Mo by volume.

\subsection{Thermal Diffusivity Measurements and Results}

The laser flash method [18], [19] was used to measure thermal diffusivity $(\alpha)$ of disc-shaped samples with nominal dimensions of 2-3 mm thickness and $12.5 \mathrm{~mm}$ diameter. Laser flash diffusivity measurements were performed using a Flashline 5000 (Anter Corporation, Pittsburg, PA), and thermal diffusivity data was analyzed using the Clark and Taylor method [20]. Samples were measured in accordance with ASTM E1461 [21]. Specimens were coated with carbon on both sides to ensure a consistent emissivity and absorption. Thermal diffusivity was measured in the temperature range of 100 to $1000{ }^{\circ} \mathrm{C}$ in a $\mathrm{N}_{2}$ atmosphere.

The measured thermal diffusivity data are presented in Figure 5. Each plotted value is an average of three measurements. Measured thermal diffusivity data are compared to previously published data for hot pressed AIN and AIN:Mo (30\% Mo by vol.) from Khan et al. [11]. Measured thermal diffusivity values for the authors' AIN:Mo composites were found to be slightly higher than those of Khan et al. at temperatures up to $600{ }^{\circ} \mathrm{C}$. Above $600{ }^{\circ} \mathrm{C}$, the $30 \%$ Mo composite of Khan et al. was found to have thermal diffusivity values approximately equal to the average of the measured thermal diffusivity values for the authors' composites for a given temperature. 


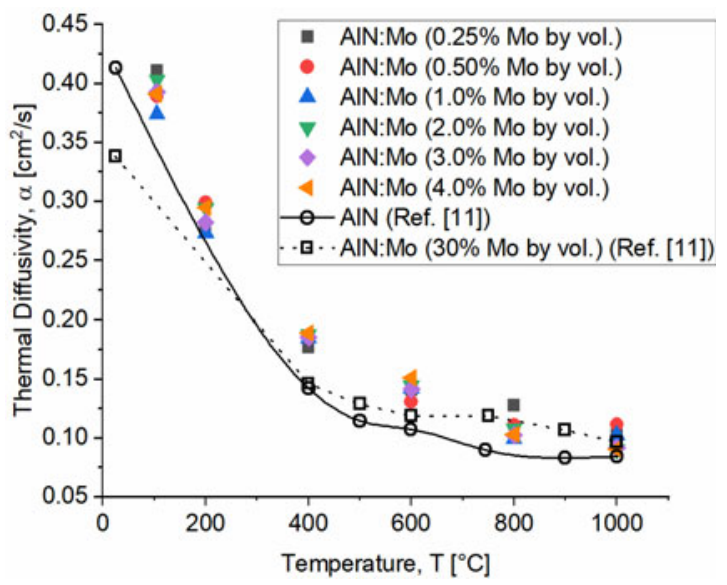

Figure 5. High temperature thermal diffusivity data for AIN:Mo composites ranging from $0.25 \%$ to $4.0 \%$ Mo by volume. Measured data is overlaid with literature data for hot-pressed AIN and AIN:Mo (30\% Mo by vol.) from Khan et al. [11].

\section{$\underline{\text { 3.4 Thermal Conductivity Calculations, Results, and Discussion }}$}

The thermal conductivity $(\mathrm{k})$ of AIN is dependent on processing additives, such as yttrium and lanthanide compounds, used to assist densification and oxygen removal during sintering [9]. The presence of free oxygen during densification enables aluminate phase formation, which has a direct negative effect on thermal conductivity. Typically, thermal conductivity of AIN realizes a maximum between 5-8\% (vol.) sintering additive [9].

Thermal conductivity $(\mathrm{k})$ can be calculated from thermal diffusivity $(\alpha)$, density $(\rho)$ and specific heat capacity $\left(\mathrm{C}_{\mathrm{p}}\right): \mathrm{k}=\alpha \rho \mathrm{C}_{\mathrm{p}}$. The uncertainty in $\mathrm{k}$ is estimated to be $10 \%$. Figure 6 shows temperature dependent thermal conductivity data for AlN:Mo composites $\left(\mathrm{k}_{\mathrm{c}}\right)$ with Mo concentrations of $0.25 \%$ to $4.0 \%$ by vol. The results show no strong dependence on Mo content. Literature data for elemental Mo [22] and hot pressed AlN with $\mathrm{Y}_{2} \mathrm{O}_{3}$ additives [9] are also plotted in Figure 6 for reference. The $\mathrm{k}_{\mathrm{c}}$ temperature dependence is dominated by the AlN matrix, showing a strong reduction in thermal conductivity with increasing temperature. The $k_{c}$ measurements generally fall below the literature values of the AIN (with $4 \%$ yttria by wt.) [9]. 


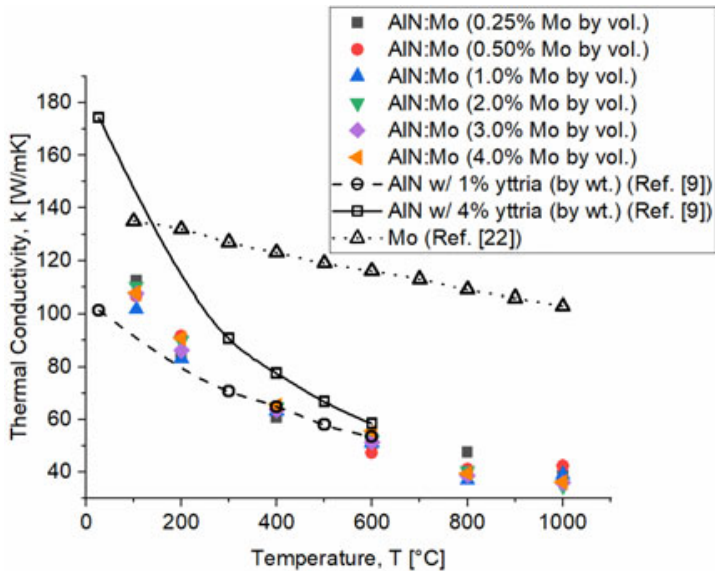

Figure 6. High temperature thermal conductivity data for AlN:Mo composites ranging from $0.25 \%$ to $4.0 \%$ Mo by volume. Experimental data is overlaid with literature data for AlN with $1 \%$ and $4 \%$ yttria (by wt.) [9] and for Mo [22].

\section{ANALYSIS}

The thermal conductivity of a composite depends on constituent thermal conductivity, constituent volume fraction, minor constituent particle size and distribution, and the existence of an interfacial thermal barrier between the matrix and particle. Modeling by Hasselman and Johnson [23] shows the effective thermal conductivity of a continuous matrix with dilute volume fractions of non-interacting spherical inclusions as Equation (2).

$$
k_{c}=k_{m}\left[2\left(\frac{k_{d}}{k_{m}}-\frac{k_{d}}{r h_{c}}-1\right) V_{d}+\frac{k_{d}}{k_{m}}+\frac{2 k_{d}}{r h_{c}}+2\right] /\left[\left(1-\frac{k_{d}}{k_{m}}+\frac{k_{d}}{r h_{c}}\right) V_{d}+\frac{k_{d}}{k_{m}}+\frac{2 k_{d}}{r h_{c}}+2\right]
$$

where $\mathrm{k}$ is the thermal conductivity; $\mathrm{V}_{\mathrm{d}}$ is the volume fraction of the dispersed phase; subscripts $\mathrm{c}, \mathrm{m}$, and $\mathrm{d}$ refer to the composite, matrix, and dispersed phase, respectively; $r$ is the radius of the particle inclusion; and $h$ is the thermal boundary conductance. Equation (2) reduces to the Maxwell equation (Equation (3)) [24] for the case of no thermal interfacial resistance $\left(\mathrm{h}_{\mathrm{c}}=\infty\right)$ :

$$
k_{c,\left(h_{c}=\infty\right)}=k_{m}\left[2\left(\frac{k_{d}}{k_{m}}-1\right) V_{d}+\frac{k_{d}}{k_{m}}+2\right] /\left[\left(1-\frac{k_{d}}{k_{m}}\right) V_{d}+\frac{k_{d}}{k_{m}}+2\right]
$$
Equation (4):

In the opposite extreme, where $h_{c}$ is assumed to be zero, Equation (2) reduces to

$$
k_{c,\left(h_{c}=0\right)}=2 k_{m} \frac{\left(1-V_{d}\right)}{\left(2+V_{d}\right)}
$$

The matrix thermal conductivity $\left(\mathrm{k}_{\mathrm{m}}\right)$ for the particular AlN formulation used in the present study was stated by the vendor [6] to be $150+/-5 \mathrm{~W} / \mathrm{mK}$ at $25{ }^{\circ} \mathrm{C}$. The thermal conductivity of the molybdenum dispersed phase, $\mathrm{k}_{\mathrm{d}}$, at $25^{\circ} \mathrm{C}$ was estimated to 
be $137 \mathrm{~W} / \mathrm{mK}$ using a linear regression of data from Ho et al. [22], as shown in Figure 7. Using the $4.0 \%$ Mo (vol.) AlN:Mo composite as a test case, the composite thermal conductivity $\left(\mathrm{k}_{\mathrm{c}}\right)$ can be calculated using an exponential fit of the relevant experimental data (plotted previously in Figure 6), as depicted in Figure 7. Using this fit, $\mathrm{k}_{\mathrm{c}}$ for the $4.0 \%$ Mo composite is estimated to be $127 \mathrm{~W} / \mathrm{mK}$ at $25{ }^{\circ} \mathrm{C}$. It becomes apparent that when the vendor-provided matrix thermal conductivity $(\mathrm{km}=150+/-5 \mathrm{~W} / \mathrm{mK})$ and the dispersed phase thermal conductivity $\left(\mathrm{k}_{\mathrm{d}}=137 \mathrm{~W} / \mathrm{mK}\right)$ are in excess of the measured thermal conductivity of the composite $\left(\mathrm{k}_{\mathrm{c}}=124 \mathrm{~W} / \mathrm{mK}\right)$, the Maxwell equation (Equation (3)) overestimates the thermal conductivity of the present AlN:Mo material system as $149 \mathrm{~W} / \mathrm{mK}\left(\right.$ for $\left.\mathrm{k}_{\mathrm{m}}=150\right)$.

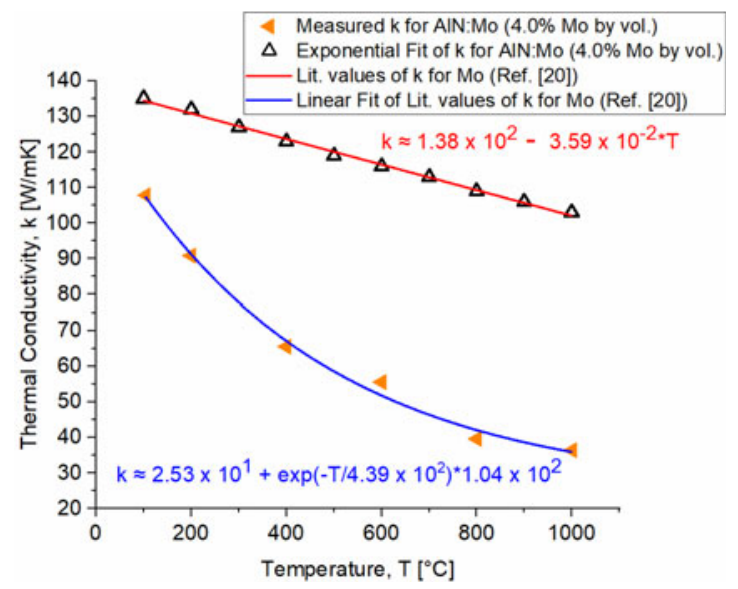

Figure 7. Measured thermal conductivity data for AIN:Mo (4.0\% Mo by vol.), literature values of thermal conductivity for Mo from Ref. [22], and associated curve fits.

The method of Hasselman and Johnson [23] (Equation (2)) can be used to determine if the drop in thermal conductivity of the composite, compared to the matrix, can be readily explained by the presence of finite thermal interfacial resistance $\left(h_{c}\right)$ at the boundary of the dispersed Mo particles. For the purposes of this determination, the authors note that: 1) uncertainty in the thermal conductivity of the present AIN:Mo composite is taken into account, 2) the range of vendor-provided matrix thermal conductivity values is taken into account without accounting for additional uncertainty, 3 ) dispersed phase thermal conductivity and volume fraction of the dispersed phase will be treated as exact (i.e., uncertainty is ignored), and 4) assumptions implicit in the Hasselman and Johnson model, such as the requirement that the material system be far from the percolation threshold, remain in effect. The relevant values for this determination are: experimentally determined $\mathrm{k}_{\mathrm{c}}($ AlN:Mo, $4 \%$ Mo by vol. $)=124$ $\mathrm{W} / \mathrm{mK}+/-10 \%, \mathrm{k}_{\mathrm{m}}=150+/-5 \mathrm{~W} / \mathrm{mK}, \mathrm{k}_{\mathrm{d}}=137 \mathrm{~W} / \mathrm{mK}, \mathrm{V}_{\mathrm{d}}=0.04$.

Using calculations based on Equation (2), curves of $k_{c}$ for three $k_{m}$ values (145 $\mathrm{W} / \mathrm{mK}, 150 \mathrm{~W} / \mathrm{mK}$, and $155 \mathrm{~W} / \mathrm{mK}$ ), are plotted in Figure 8 for a wide range of values of $\mathrm{rh}_{\mathrm{c}}$. This term represents the radius of the particle inclusions (r) multiplied by the thermal interfacial resistance $\left(h_{c}\right)$. The upper and lower asymptotes of the $k_{c}$ curves represent values calculated by Equation (3) and Equation (4), respectively. 
Experimental values for the AlN:Mo (4\% Mo by vol.) composite $\mathrm{k}_{\mathrm{c}}$ are overlaid with the Equation (2) $\mathrm{k}_{\mathrm{c}}$ curves. The calculated and experimental curve sets approach at the lowest values of $\mathrm{rh}_{\mathrm{c}}$ for the $4 \%$ Mo composite (the shaded region in Figure 8 ) but do not overlap; thus, a finite $h_{c}$ at the Mo particle boundaries does not adequately account for the reduction in thermal conductivity observed in the composite (compared to the virgin AlN matrix). Because the independent variable was chosen as $\mathrm{rh}_{\mathrm{c}}$ and due to the asymptotic response of the function at extreme values, any combination of particle radius and thermal barrier resistance that satisfies the assumptions of Hasselman and Johnson's effective medium model will represent a composite having a thermal conductivity value that falls somewhere between the upper and lower asymptotes of the curve representing the assumed $\mathrm{k}_{\mathrm{m}}$ value.

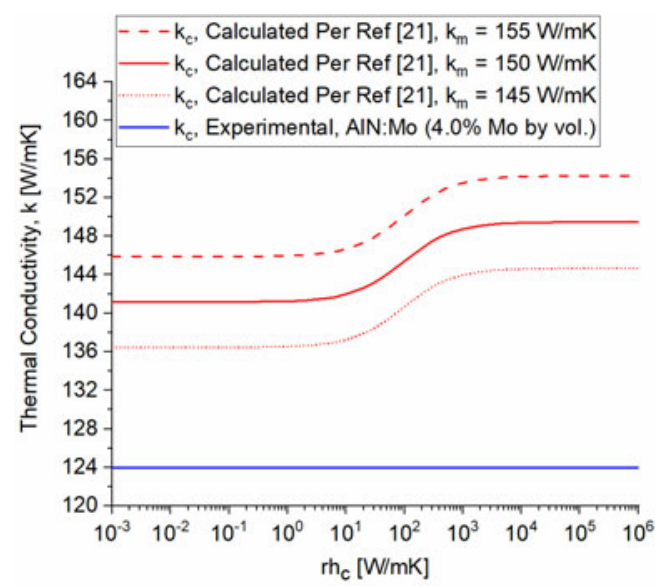

Figure 8. Calculated $\mathrm{k}_{\mathrm{c}}$ value curves, based on Equation (2) [23], overlaid with experimental $\mathrm{k}_{\mathrm{c}}$ values for AIN:Mo (4.0\% Mo by vol.)

As described previously, the thermal conductivity of AlN is extremely sensitive to the presence of free oxygen during the sintering process [7]-[9]. The authors believe that a significant contributor to the reduction in thermal conductivity of the AlN:Mo composite, compared to the virgin AlN matrix, is due to the inadvertent addition of oxygen when Mo is added to the matrix material prior to sintering. Chhillar et al. indicate that due to the relatively large surface area of the Mo microparticles, formation of thin oxide layers or layers of adsorbed free oxygen are possible [25]. Thus, pretreatment of the Mo powder to remove oxygen [26] or the adjustment of oxygengettering sintering additive concentrations [7], [9] may potentially enable AlN:Mo composites with higher thermal conductivity.

\section{SUMMARY}

In order to begin to evaluate and model the suitability of high temperature ceramic composites, such as AlN:Mo, as susceptor materials for power beaming applications, the electromagnetic, thermal, and mechanical properties of the material must be known at elevated temperatures. Work reported here focused on the 
development of thermal property datasets for AlN:Mo composites ranging from $0.25 \%$ to $4.0 \%$ Mo by volume.

To calculate thermal conductivity of the AlN:Mo composite series, specific heat capacity, thermal diffusivity, and density data were acquired. The calculated specific heat capacity, $\mathrm{C}_{\mathrm{p}}$, of the set of AlN:Mo composites was, on average, found to be approximately $803 \mathrm{~J} / \mathrm{kgK}$ at $100{ }^{\circ} \mathrm{C}$ and to increase to approximately $1133 \mathrm{~J} / \mathrm{kgK}$ at 1000 ${ }^{\circ} \mathrm{C}$, with all values found to be within $+/-32 \mathrm{~J} / \mathrm{kgK}$ of the average at a given temperature. These calculated specific heat capacity values matched values derived from DSC measurements to within the expected error of the measurements. Measured thermal diffusivity, $\alpha$, of the set of AlN:Mo composites was, on average, found to be approximately $3.93 \times 10^{-1} \mathrm{~cm}^{2} / \mathrm{s}$ at $100{ }^{\circ} \mathrm{C}$ and to increase to approximately $9.80 \times 10^{-2}$ $\mathrm{cm}^{2} / \mathrm{s}$ at $1000{ }^{\circ} \mathrm{C}$, with all values within $+/-1.84 \times 10^{-2} \mathrm{~cm}^{2} / \mathrm{s}$ of the average at a given temperature. The measured density, $\rho$, of the set of AlN:Mo composites was found to vary linearly with added Mo and to follow the relationship described by Equation (1). Thermal conductivity, $\mathrm{k}$, for the set of AlN:Mo composites was found to be approximately $108 \mathrm{~W} / \mathrm{mK}$ at $100{ }^{\circ} \mathrm{C}$ and to decrease to approximately $38 \mathrm{~W} / \mathrm{mK}$ at 1000 ${ }^{\circ} \mathrm{C}$, with all values within $+/-5.3 \mathrm{~W} / \mathrm{mK}$ of the average at a given temperature. Data trends show increasing Mo content correlates to reductions of $\mathrm{C}_{\mathrm{p}}, \alpha$, and $\mathrm{k}$ at a given temperature.

Comparisons of composite thermal conductivity predicted using the method of Hasselman and Johnson [23] (Equation (2)) and experimentally measured values of the present AlN:Mo composites suggest that the process of adding Mo to the virgin AlN matrix material results in an overall reduction of thermal conductivity that cannot be explained by the thermal conductivity of the Mo grains even if finite thermal interfacial resistance at the grain boundaries is taken into account. The inadvertent addition of oxygen when the Mo is added to the matrix material prior to sintering may be a significant contributor to the reduction in thermal conductivity of the AIN:Mo composite (compared to the virgin AlN matrix). As a result, that pretreatment of the Mo powder to remove oxygen or adjustment of oxygen-gettering sintering additive concentrations may enable AlN:Mo composites with higher thermal conductivity.

\section{ACKNOWLEDGMENTS}

B. W. Hoff, M. S. Hilario, and A. E. Baros were funded by the Air Force Office of Scientific Research under FA9550-17RDCOR449 and by the Operational Energy Capability Improvement Fund (OECIF). S. C. Hayden, R. O. Grudt, and M. L. Ostraat were funded by Aramco Services Company. F. W. Dynys was supported by funding provided by the Air Force Research Laboratory. The authors acknowledge helpful discussions with E. Savrun of Sienna Technologies, Inc. and with A. Sayir of the Air Force Office of Scientific Research.

\section{REFERENCES}

1. B.W. Hoff, M.S. Hilario, B. Jawdat, A.E. Baros, F.W. Dynys, J.A. Mackey, V. V. Yakovlev, C.E. Andraka, K.M. Armijo, E. Savrun, and I.M. Rittersdorf, in 2018 Proc. IMPI's 52nd Annu. Microw. Power Symp. (International Microwave Power Institute, Long Beach, CA, 2018), pp. 82-83.

2. B.W. Hoff, M. Hilario, B. Jawdat, D. Agrawal, M. Lanagan, J. Cheng, and F. Dynys, in Proc. 12th Pacific Rim Conf. Ceram. Glas. Technol. (The Americal Ceramic Society, Waikoloa, HI, 2017), p. 61. 
3. M.S. Hilario, B.W. Hoff, M.P. Young, and M.T. Lanagan, in 53rd AIAA Aerosp. Sci. Meet. (AIAA SciTech Forum, Kissimmee, FL, 2015), pp. 1-10.

4. J.M. Gaone, B.S. Tilley, and V. V. Yakovlev, in 2017 IEEE MTT-S Int. Microw. Symp. (IEEE, 2017), pp. 459-462.

5. V. V. Yakovlev, S.M. Allan, M.L. Fall, and H.S. Shulman, in Microw. RF Power Appl., edited by J. Tao (Cépaduès Éditions, Toulouse, 2011), pp. 303-306.

6. "Sienna Technologies, Inc." [Online]. Available: http://siennatech.com/. [Accessed: 06Nov-2018].

7. J.H. Cooper, Process-Dependence of Properties in High Thermal Conductivity Aluminum Nitride Substrates for Electronic Packaging, Naval Postgraduate School, 1991.

8. G.W. Prohaska and G.R. Miller, MRS Proc. 167, 215 (1989).

9. T.B. Jackson, A. V. Virkar, K.L. More, R.B. Dinwiddie, and R.A. Cutler, J. Am. Ceram. Soc. 80, 1421 (2005).

10. Y. Kurokawa, K. Utsumi, and H. Takamizawa, J. Am. Ceram. Soc. 71, 588 (1988).

11. A.A. Khan and J.C. Labbe, J. Eur. Ceram. Soc. 17, 1885 (1997).

12. A.A. Khan and J.C. Labbe, Mater. Sci. Eng. A 230, 33 (1997).

13. A.A. Khan and J.C. Labbe, J. Eur. Ceram. Soc. 16, 739 (1996).

14. M.W. Chase, J. Phys. Chem. Ref. Data, Monogr. 9, 1 (1998).

15. Y. Liu, Y. Jiang, R. Zhou, X. Liu, and J. Feng, Ceram. Int. 41, 5239 (2015).

16. J.E. Hurst and B.K. Harrison, Chem. Eng. Commun. 112, 21 (1992).

17. P. Gabbott, in edited by P. Gabbott (Blackwell Publishing Ltd., Oxford, UK, (2008), pp. $1-50$.

18. W.J. Parker, R.J. Jenkins, C.P. Butler, and G.L. Abbott, J. Appl. Phys. 32, 1679 (1961).

19. L. Vozár and W. Hohenauer, High Temp. - High Press. 35-36, 253 (2003).

20. L.M. Clark and R.E. Taylor, J. Appl. Phys. 46, 714 (1975).

21. ASTM International, ASTM E1461-13 Standard Test Method for Thermal Diffusivity by the Flash Method (West Conshohocken, PA, 2016).

22. C.Y. Ho, R.W. Powell, and P.E. Liley, Thermal Conductivity of Selected Materials Part 2 (National Standard Reference Data Series 16, National Bureau of Standards, Washington, D.C., 1968).

23. D.P.H. Hasselman and L.F. Johnson, J. Compos. Mater. 21, 508 (1987). 
24. J.C. Maxwell, A Treatise on Electricity and Magnetism, Vol. I, 3rd ed. (Oxford University Press, Oxford, UK, 1904).

25. P. Chhillar, D. Agrawal, and J.H. Adair, Powder Metall. 51, 182 (2008).

26. B.-S. Kim, E. Kim, H.-S. Jeon, H.-I. Lee, and J.-C. Lee, Mater. Trans. 49, 2147 (2008). 